\title{
Bruk av videosamtale i behandling av tuberkulose-sykdom i Nord-Norge
}

ORIGINALARTIKKEL

\section{RENATE BENDIKSEN}

E-post: renate.bendiksen@unn.no Avdeling for mikrobiologi og smittevern

Universitetssykehuset Nord-Norge

Hun har vært prosjektmedarbeider i studien VDOT tuberkulose og har bidratt med idé, utforming/design, innsamling, analyse og tolkning av data, litteratursøk, utarbeiding/revisjon av selve manuset og godkjenning av innsendte manusversjon.

Renate Bendiksen er infeksjonssykepleier og tuberkulosekoordinator.

Forfatteren har fylt ut ICMJE-skjemaet og oppgir ingen interessekonflikter.

\section{TONE OVESEN}

Avdeling for mikrobiologi og smittevern

Universitetssykehuset Nord-Norge

Hun har vært prosjektleder for studien VDOT tuberkulose og har bidratt med idé, utforming/design, innsamling, analyse og tolkning av data, litteraturs $\emptyset \mathrm{k}$, utarbeiding/revisjon av selve manuset og godkjenning av innsendte manusversjon.

Tone Ovesen er helsesykepleier og tuberkulosekoordinator.

Forfatteren har fylt ut ICMJE-skjemaet og oppgir ingen interessekonflikter.

\section{ANNE-METTE ASFELDT}

Avdeling for mikrobiologi og smittevern

Universitetssykehuset Nord-Norge

Institutt for samfunnsmedisin

UiT - Norges arktiske universitet

Hun har bidratt med utforming/design, analyse og tolkning av data, utarbeiding/revisjon av selve manuset og godkjenning av innsendte manusversjon.

Anne-Mette Asfeldt er ph.d. og spesialist i infeksjonssykdommer. Hun er rådgivende

smittevernoverlege for Finnmarkssykehuset og førsteamanuensis.

Forfatteren har fylt ut ICMJE-skjemaet og oppgir ingen interessekonflikter.

\section{DAG SEEGER HALVORSEN}

Seksjon for infeksjonssykdommer

Universitetssykehuset Nord-Norge

Institutt for klinisk medisin

UiT - Norges arktiske universitet

Han har bidratt med analyse og tolkning av data, utarbeiding/revisjon av selve manuset og godkjenning av innsendte manusversjon.

Dag Seeger Halvorsen er ph.d. og spesialist i infeksjonssykdommer og i medisinsk mikrobiologi. Han er overlege og førsteamanuensis.

Forfatteren har fylt ut ICMJE-skjemaet og oppgir ingen interessekonflikter. 
Avdeling for resistens- og infeksjonsforebygging

Folkehelseinstituttet

Avdeling for mikrobiologi og smittevern

Universitetssykehuset Nord-Norge

Hun har vært veileder for studien VDOT tuberkulose og har bidratt med idé, utforming/design,

analyse og tolkning av data, litteratursøk, utarbeiding/revisjon av selve manuset og godkjenning av innsendte manusversjon.

Kirsten Gravningen er ph.d., spesialist i medisinsk mikrobiologi og regional smittevernoverlege.

Forfatteren har fylt ut ICMJE-skjemaet og oppgir ingen interessekonflikter.

Renate Bendiksen og Tone Ovesen har bidratt i like stor grad til denne artikkelen.

\section{BAKGRUNN}

Totalt ble det meldt 261 pasienter med tuberkulose i Norge i 2017, hvorav $90 \%$ fullførte behandlingen. Tuberkulosemedikamenter gis som daglig direkte observert behandling (DOT) til alle pasienter. Vi undersøkte om dette kan gjøres ved videosamtale.

\section{MATERIALE OG METOdE}

Vi gjennomførte en klinisk observasjonsstudie ved Universitetssykehuset Nord-Norge 2016-19, der pasienter $\geq 16$ år med tuberkulosesykdom etter minimum to uker daglig direkte observert behandling ved hjemmebes $ø$ fortsatte behandlingen ved videosamtale. Norsk Helsenetts passordbeskyttede krypterte videosamtaletjeneste ble benyttet. Hjemmesykepleien kontaktet pasienten via videosamtale i sanntid og observerte medikamentinntaket via nettbrett, smarttelefon eller pc.

\section{RESULTATER}

20 av 30 pasienter oppfylte inklusjonskriteriene, hvorav 17 pasienter (15 utenlandsfødte) med median alder 32 (17-74) år ble inkludert. Gjennomsnittlig observert medikamentinntak per pasient var $86,1 \%$ i perioden med direkte observert behandling ved hjemmebesøk og $75,9 \%$ i perioden ved videosamtale. Median daglig tidsbruk for hjemmesykepleien var 17 (2-40) minutter ved hjemmebesøk og 3 (1-8) minutter ved videosamtale. 14 av 17 pasienter og 14 av 17 hjemmesykepleiere foretrakk videosamtale fremfor hjemmebes $\emptyset$ k. 15 pasienter og alle hjemmesykepleiere ville anbefalt videosamtale til andre. Tekniske problemer $(8,9 \%)$ var vanligste årsak til at direkte observert behandling ikke ble utført i periode med videosamtale.

\section{FORTOLKNING}

Direkte observert behandling ved videosamtale var gjennomførbart hos utvalgte pasienter. Videosamtale var tidsbesparende for hjemmesykepleien og ble foretrukket fremfor hjemmebesøk.

Tuberkulose er den infeksjonssykdommen som tar flest liv i verden (1), men forekomsten i Norge er synkende og blant verdens laveste (2). I 2017 ble 261 pasienter med tuberkulose meldt til Folkehelseinstituttet, hvorav 89\% var utenlandsfødte (2). Median alder var 30 år. $90 \%$ av pasientene fullførte tuberkulosebehandlingen (3), og Norge nådde dermed Verdens helseorganisasjons mål om at 90 \% eller flere skal fullføre behandlingen (4). Forskrift om tuberkulosekontroll anbefaler at tuberkulosemedikamenter gis som daglig direkte observert behandling (DOT) til alle pasienter, men det gjøres individuelle tilpasninger i tråd med anbefalinger fra Verdens helseorganisasjon $(1,5-7)$.

Mangelfull etterlevelse av tuberkulosebehandling kan medføre behandlingssvikt og resistensutvikling (1). Direkte observert behandling skal sikre at behandlingen fullføres ved at helsepersonell observerer at pasienten inntar og svelger alle doser tuberkulosemedikamenter (6). Medikamentene tas én gang daglig i minimum seks 
måneder (1). I Norge delegeres praktisk gjennomføring av direkte observert behandling vanligvis til hjemmesykepleien, som gir medikamenter til pasienten ved hjemmebes $\emptyset \mathrm{k} \mathrm{i}$ hans/hennes hjem eller på hjemmesykepleietjenestens kontor. Tuberkulosekoordinatorer ansatt i sykehus koordinerer oppfølging og behandling av pasientene i samarbeid med legespesialist og kommunehelsetjeneste (6).

Store geografiske avstander i Norge medfører lang reisetid og krevende logistikk ved at tidspunktet for direkte observert behandling ved hjemmebes $\emptyset \mathrm{k}$ skal tilpasses både pasientens og hjemmesykepleiernes dagsplan. Daglige hjemmebes $ø \mathrm{k}$ kan utfordre taushetsplikten, og enkelte pasienter har beskrevet hjemmebes $ø \mathrm{k}$ som stigmatiserende og ydmykende (8-10).

Verdens helseorganisasjons retningslinjer fra 2017 åpner for at direkte observert behandling kan gjennomføres ved videosamtale (7). Nasjonal e-helsestrategi 2017-22 har som visjon å digitalisere helse- og omsorgstjenesten i Norge (11). Helse Nords mål er å bli ledende i landet på bruk av informasjonsteknologi i pasientbehandling for å bedre tilgjengelighet og effektivitet (12). Studier i England, USA og Australia viser at direkte observert behandling ved videosamtale er en pålitelig, kostnads- og tidsbesparende metode som ivaretar pasientens behov $(9,10,13-15)$. Videosamtale gjennomføres enten i sanntid $(10,14)$ eller ved at pasienten filmer sitt eget medikamentinntak og sender videoen til helsepersonell som ser den i ettertid $(9,13,15,16)$.

I denne studien har vi undersøkt gjennomførbarhet, andel observert og etterlevd medikamentinntak, hjemmesykepleiens tidsbruk samt pasientenes og hjemmesykepleiens vurdering av direkte observert behandling ved videosamtale i kommuner i Nord-Norge.

\section{Materiale og metode}

Dette er en klinisk observasjonsstudie av pasienter i behandling for tuberkulosesykdom ved Universitetssykehuset Nord-Norge, Troms $\emptyset$, utført i samarbeid mellom sykehuset og kommunehelsetjenesten i ti kommuner. Inklusjonsperioden var 1.9.2016-15.9.2018. Studieperioden ble avsluttet 14.3.2019. Absolutte inklusjonskriterier var alder $\geq 16$ år, $\geq$ 2 måneder igjen av behandlingsperioden og peroral behandling. Gjennom samtale med pasienten vurderte én av to tuberkulosekoordinatorer om pasienten hadde tilstrekkelig god sykdomsforståelse og motivasjon for å gjennomføre direkte observert behandling ved videosamtale.

\section{GJENNOMFØRING}

Videosamtale ble utført med Acano/Cisco Meeting, en passordbeskyttet kryptert videosamtaletjeneste via Norsk Helsenett, der samtlige kommuner og sykehus i Norge er medlemmer (17). Løsningen er godkjent for kommunikasjon innen helse- og omsorgssektoren og oppfyller EU/EØS-landenes krav til kommunikasjonssikkerhet (18-21). Norsk Helsenett har kun løsninger for kommunikasjon i sanntid. Sykehusets kvalitets- og utviklingssenter ga teknisk bistand.

Pasientene og hjemmesykepleierne fikk opplæring i bruk av direkte observert behandling ved videosamtale av tuberkulosekoordinator. Pasientene brukte egen smarttelefon, nettbrett eller pc eller lånte nettbrett av studien. Hjemmesykepleietjenesten lånte nettbrett med SIM-kort av studien. Før oppstart med videosamtale skulle pasientene ha hatt velfungerende direkte observert behandling ved hjemmebes $ø \mathrm{k}$ i minimum to uker.

Hjemmesykepleier startet videosamtale med pasienten på avtalt tidspunkt hver dag. Begge parter måtte være innlogget for å oppnå kontakt. Pasienten presenterte seg med navn og fødselsdato og filmet ansiktet slik at det var godt synlig i kameralinsen. Pasienten svelget tablettene med vann fra et gjennomsiktig glass og filmet sin tomme munnhule etter medikamentinntak. Dersom pasienten ikke besvarte videosamtalen, ringte hjemmesykepleieren til pasienten på telefon og/eller dro på hjemmebes $ø$ k. Ved tekniske problemer som forhindret videosamtale, ble det avtalt egenadministrasjon av 
tuberkulosemedikamentene eller hjemmebes $ø$. Ved vedvarende tekniske problemer ble primært tuberkulosekoordinator, eventuelt kvalitets- og utviklingssenteret, kontaktet.

Etterlevelse av medikamentinntak i henhold til avtale omfattet observert medikamentinntak og avtalt egenadministrasjon. Ved lav etterlevelse av direkte observert behandling ved videosamtale avgjorde tuberkulosekoordinator og hjemmesykepleien i fellesskap om hjemmebesøk skulle gjenopptas. I perioden med videosamtale mottok pasienten medisindosetter for $\mathbf{2 - 4}$ uker fra hjemmesykepleien, alternativt oppbevarte pasienten selv alle medikamentene.

\section{DATAINNSAMLING}

Hjemmesykepleier registrerte daglig følgende informasjon på papirskjema med fargefoto av pasienten og tablettene (for identifikasjon): utført direkte observert behandling ved hjemmebesøk eller videosamtale, eventuelle årsaker til at det ikke var utført og alternativ oppfølging, og tidsbruk i minutter ved hjemmebesøk (transporttid til-fra og varighet av pasientkontakt) og ved videosamtale (tid fra innlogging til avsluttet videosamtale). Tuberkulosekoordinator kvalitetssikret innsamlede data. Ved ikke skriftlig dokumentert medikamentinntak i hjemmesykepleien innhentet tuberkulosekoordinator hver måned telefonisk bekreftelse fra hjemmesykepleien på observert medikamentinntak både ved hjemmebesøk og ved videosamtale. I studien ble dette registrert som «ikke skriftlig dokumentert medikamentinntak». Ved ikke oppnådd kontakt med pasienten i perioden med videosamtale bekreftet pasienten muntlig sitt medikamentinntak ved påfølgende kontakt med hjemmesykepleien (registrert som «hjemmesykepleien oppnådde ikke kontakt med pasienten»). For begge type hendelser vurderte behandlende legespesialist og tuberkulosekoordinator medikamentene som tatt, og ingen pasienter i studien fikk forlenget tuberkulosebehandling som følge av dette.

Ved avsluttet behandling gjennomførte tuberkulosekoordinator strukturert intervju (spørreskjema med definerte svarkategorier og noe fritekst) av hver pasient på sykehuset eller via telefonsamtale. Tuberkulosekoordinator gjennomførte telefonintervju med én ansatt fra hver hjemmesykepleiesone (tilsvarende tilpasset spørreskjema).

\section{DATAANALYSE}

Data er presentert rent deskriptivt. Først regnet vi a) andel observerte medikamentinntak (\%), b) etterlevelse av medikamentinntak i henhold til avtale (\%) og hjemmesykepleiens gjennomsnittlige tidsbruk per dag (minutter) for hver pasient. Så beregnet vi gjennomsnitt av a) og b) for alle pasienter $(\mathrm{N}=17)$ og medianverdi av gjennomsnitt for hjemmesykepleiens tidsbruk. Vi presenterer a) og b) som gjennomsnitt (\%) med standardavvik og hjemmesykepleiens tidsbruk som medianverdi med minimums- og maksimumsverdi. Vi brukte SPSS versjon 25 .

Personvernombudet ved Universitetssykehuset Nord-Norge godkjente studien som en kvalitetsstudie (0658/20012017). Pasientene, kontaktpersonene i hjemmesykepleien og kommuneoverlegen samtykket skriftlig til deltakelse.

\section{Resultater}

30 pasienter $\geq 16$ år ble behandlet for tuberkulosesykdom i inklusjonsperioden, hvorav ti pasienter ikke fylte inklusjonskriteriene (figur 1). Av de 20 forespurte samtykket 17 til deltakelse. Median alder var 32 (17-74) år, og ni var kvinner (tabell 1). 15 pasienter var utenlandsfødte og to snakket begrenset norsk/engelsk. 12 pasienter hadde fast jobb eller studerte. 
pasienter $\geq 16$ år ibehandling for

tuberkulosesykdom ved Universitetssykehuset

Nord-Norge, Tromsø i perioden 1.9.2016-15.9.2018

10 pasienter ikke aktuelle for inklusjon i studien

Annen alvorlig sykdom/dårlig sykdomsforståelse $(n=6)$

Flytting $(n=2)$

Andre $i$ husstanden hadde direkte observert

behandling ved hjemmebesøk $(n=2)$

20 pasienterinvitert til å delta

3 pasienter ønsket ikke direkte observert behandling

ved videosamtale

17 pasienter inkludert i studien

Figur 1 Studiepopulasjonen i en klinisk observasjonsstudie der man så på direkte observert behandling ved hjelp av videosamtale for pasienter $\geq 16$ år med tuberkulosesykdom.

\section{Tabell 1}

Karakteristikk av de 17 pasientene som fikk direkte observert behandling ved videosamtale i ti kommuner i Nord-Norge i perioden 1.9.2016-14.3.2019.

\begin{tabular}{|lr|}
\hline Karakteristika & Antall \\
\hline Alder i år, median (min-maks) & 32 (17-74) \\
\hline Kjønn Kvinner & 9 \\
\hline Menn & 8 \\
\hline Europa & 4 \\
\hline Afrika & 8 \\
\hline Asia & 5 \\
\hline Fødeverdensdel & $7(2-16)$ \\
\hline Arr bodd i Norge for utenlandsfødte (n =15), median (min-maks) & 15 \\
\hline Språk & 2 \\
\hline Begrenset norsk/engelsk & 6 \\
\hline Jobber & 6 \\
\hline Studerer & 5 \\
\hline Annet & 11 \\
\hline Daglig virke & 6 \\
\hline Kun tuberkulose & 6 \\
\hline Tuberkulose og annen langvarig sykdom & 11 \\
\hline Komorbiditet & \\
\hline Type tuberkulosesykdom & \\
\hline & \\
\hline & \\
\hline & \\
\hline
\end{tabular}

${ }^{1}$ Inkluderer pasienter med kun lungetuberkulose eller lungetuberkulose og samtidig affeksjon av annet organ

\section{DAGLIG OPPFØLGING AV MEDIKAMENTINNTAK}

Til tross for at det var planlagt to uker med direkte observert behandling ved hjemmebesøk 
før oppstart av videosamtale, startet tre pasienter videosamtale etter bare o-5 dager med hjemmebesøk.

Median oppfølgingstid var 3(o-16) uker ved hjemmebesøk og 24 (9-53) uker ved videosamtale (tabell 2). I perioden med hjemmebesøk ble medikamentinntak observert på hjemmesykepleietjenestens kontor for 2 av 17 pasienter. Øvrige fikk hjemmebes $ø$ k. Åtte pasienter utførte oftest videosamtale hjemmefra, mens ni utførte videosamtale i hjemmet, på jobb, utendørs og på reise. Gjennomsnittlig observert medikamentinntak per pasient var 86,1\% i perioden med hjemmebes $\emptyset \mathrm{k}$ og 75,9\% i perioden med videosamtale (tabell 2). Etterlevelse av medikamentinntak i henhold til avtale var 95,4\% i perioden med hjemmebes $\emptyset \mathrm{k}$ og $89,8 \%$ med videosamtale. Det var stor variasjon mellom pasientene i gjennomføring av medikamentinntak i perioden med videosamtale (figur 2).

\section{Tabell 2}

Oppfølgingstid, observerte medikamentinntak, etterlevelse av medikamentinntak iht. avtale og hjemmesykepleiens tidsbruk for direkte observert behandling ved hjemmebes $ø \mathrm{k}$ og ved videosamtale for 17 pasienter i ti kommuner i Nord-Norge i perioden 1.9.2016-14.3.2019.

\begin{tabular}{|lrr|}
\hline & Hjemmebesøk Videosamtale \\
\hline Totalt antall dager i studieperioden & 608 & 3023 \\
\hline Oppfølgingstid, median antall uker (min-maks) & $3(0-16)$ & $24(9-53)$ \\
\hline Observert medikamentinntak, gjennomsnitt (SD) & $86,1 \%(26,0)$ & $75,9 \%(19,1)$ \\
\hline $\begin{array}{l}\text { Etterlevelse av medikamentinntak iht. avtale', gjennomsnitt } \\
\text { (SD) }\end{array}$ & $95,4 \%(8,3)$ & $89,8 \%(11,3)$ \\
\hline $\begin{array}{l}\text { Hjemmesykepleiens tidsbruk, median antall minutter (min- } \\
\text { maks) }\end{array}$ & $17(2-40)$ & $3(1-8)$ \\
\hline
\end{tabular}

${ }^{1}$ Etterlevelse av medikamentinntak i henhold til avtale omfattet observert medikamentinntak og avtalt egenadministrasjon.

${ }^{2}$ Manglende data for tidsbruk var henholdsvis 48,4\% (294 av 608 dager) for periode med direkte observert behandling ved hjemmebes $ø \mathrm{k}$ og 4,2\% (127 av 3 o23 dager) ved videosamtale.

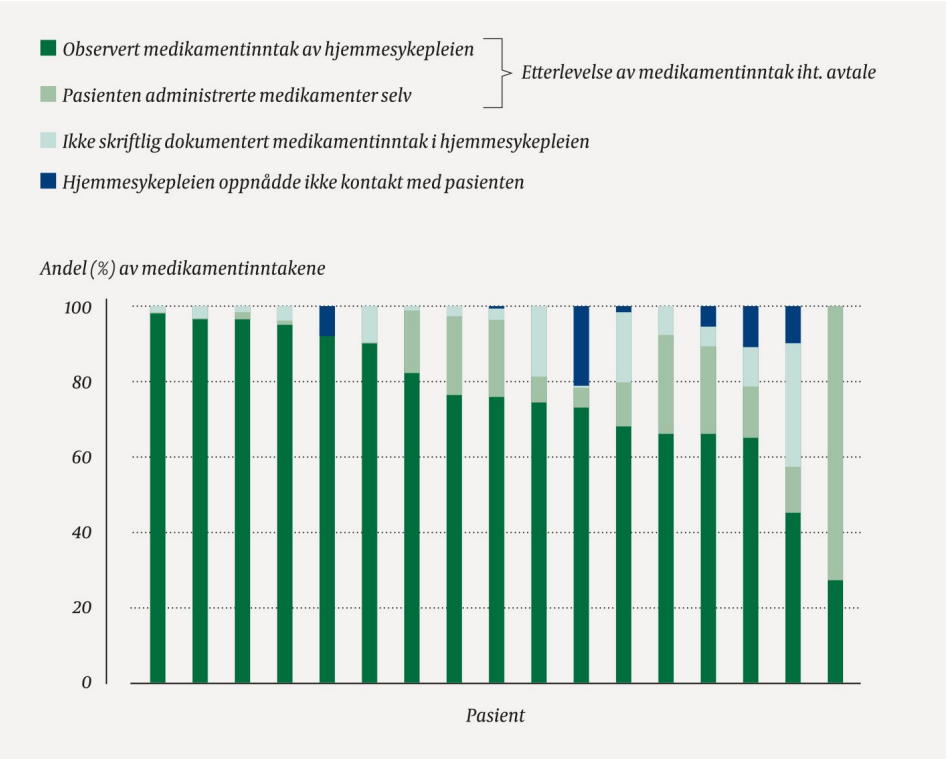

Figur 2 Gjennomføring av medikamentinntak i perioden med direkte observert behandling ved videosamtale for hver pasient.

Ved studieslutt hadde 16 av 17 pasienter fullført tuberkulosebehandlingen. Den siste 
pasienten fullførte etter at studieperioden var avsluttet.

\section{TIDSBRUK}

Hjemmesykepleiens mediane tidsbruk ved direkte observert behandling var henholdsvis 17 (2-40) minutter ved hjemmebes $\varnothing \mathrm{k}$ og 3 (1-8) minutter ved videosamtale (tabell 2).

Elleve pasienter rapporterte mindre egen tidsbruk ved videosamtale enn hjemmebesøk, mens to pasienter rapporterte at videosamtale tok lengre tid fordi de etter innlogging måtte vente på at hjemmesykepleien tok kontakt.

\section{PRAKTISKE OG TEKNISKE PROBLEMER}

Alle pasientene mestret den digitale teknologien. To pasienter gjenopptok hjemmebes $\varnothing \mathrm{k}$ de siste ukene av behandlingen fordi det oppsto praktiske og/eller tekniske problemer (ramme 1). Fem hjemmesykepleiere rapporterte at det ofte var praktiske problemer med å utføre direkte observert behandling ved videosamtale, sju rapporterte sjelden og fem aldri. Manglende punktlighet både blant pasientene og hjemmesykepleierne var årsak til flere praktiske problemer.

\section{Ramme 1 Praktiske og tekniske problemer ved gjennomføring av direkte}

\section{observert behandling ved videosamtale hos pasienter i ti kommuner i Nord-}

\section{Norge i perioden 1.9.2016-14.3.2019.}

\section{PRAKTISKE PROBLEMER}

Pasienten svarte ikke når han/hun ble kontaktet

Pasienten eller hjemmesykepleierne hadde glemt tidspunktet

Hjemmesykepleierne fant ikke nettbrett eller registreringsskjemaet

Nettbrettet var utladet

Filming av medikamentinntak var utilfredsstillende

Hjemmesykepleier hadde ikke dokumentert medikamentinntaket skriftlig

\section{TEKNISKE PROBLEMER}

Lyden og/eller bildet forsvant

Bildet var ustabilt

Videosamtaletjenesten ble brutt eller var ute av funksjon

WiFi-dekningen var dårlig

Mobilnettet manglet

Tekniske problemer (8,9\%, 268 av 3 o23 dager i perioden med videosamtale) var vanligste enkeltårsak til at direkte observert behandling ved videosamtale ikke ble utført.

\section{HJEMMEBESØK VS. VIDEOSAMTALE}

Elleve pasienter mente taushetsplikten ble best ivaretatt ved videosamtale, mens seks svarte «vet ikke». Pasientene supplerte med uttalelser som: «Det var veldig synlig når uniformerte pleiere kom hjem til meg. Det bor ingen gamle i nabolaget» og «Det var en fordel med DOT ved videosamtale. Jeg følte meg mer fri fordi jeg kunne ta medisiner hvor som helst og jeg kunne reise». 14 av 17 pasienter foretrakk videosamtale fremfor hjemmebesøk, og 15 ville anbefalt videosamtale til andre.

14 av 17 hjemmesykepleiere foretrakk videosamtale fremfor hjemmebes $\emptyset \mathrm{k}$, og alle $ø$ nsket at videosamtale skulle videreføres for nye pasienter. Én hjemmesykepleier utdypet:

«Hjemmesykepleien slapp å kjøre den lange veien til pasienten og sparte mye tid på det. Pasienten var friere til å leve sitt liv, det var veldig positivt.» 


\section{Diskusjon}

Vår studie viste at direkte observert behandling ved videosamtale var gjennomførbart for utvalgte pasienter, og tidsbesparende i kommuner i Nord-Norge. Andel observerte medikamentinntak og etterlevelse av medikamentinntak i henhold til avtale var høy både i periode for hjemmebes $\varnothing \mathrm{k}$ og videosamtale. Flertallet av pasienter og hjemmesykepleiere foretrakk videosamtale fremfor hjemmebesøk.

Vår studie forutsatte at medikamentinntak var skriftlig dokumentert av hjemmesykepleien for at medikamentinntaket skulle registreres som observert. På telefonisk forespørsel fra tuberkulosekoordinator i ettertid bekreftet hjemmesykepleien at medikamentinntaket med høy sannsynlighet var observert tross manglende dokumentasjon både ved hjemmebes $ø \mathrm{k}$ og videosamtale. Derfor var reell observasjon av medikamentinntak sannsynligvis høyere enn vi rapporterer her. Utfylling av studiens papirskjema kom i tillegg til hjemmesykepleiens egen dokumentasjon i pasientjournalen. Tidspress og involvering av mange ansatte kan forklare manglende registreringer.

Høy andel observerte medikamentinntak og etterlevelse i henhold til avtale i initial periode med hjemmebesøk kan forklares med at dette var tidlig i behandlingen, perioden var kort og pasientene var motivert for overgang til videosamtale. I likhet med andre fant vi at videosamtale er en gjennomførbar metode for å observere inntak av tuberkulosemedikamenter (13-15, 22). Andelen observerte medikamentinntak og etterlevelse ved videosamtale i vår studie samsvarer med eller er høyere enn i internasjonale studier $(9,15,16)$. Én årsak kan være at vi i vår studie ga tilbud om videosamtale til alle pasienter med tuberkulosesykdom som ifølge norske retningslinjer ellers ville fått daglig hjemmebes $ø$ k. I flere land, for eksempel Storbritannia, er direkte observert behandling forbeholdt risikogrupper med dårlig etterlevelse av medikamentinntak pga. psykisk sykdom, hjemløshet, rusproblemer e.l. (15). Etterlevelse av videosamtale i slike selekterte grupper kan bli tilsvarende lav.

Tekniske problemer hindret utføring av videosamtale i 8,9\% av perioden, mot 4,4 \% i en studie i USA (23). Vi erfarte at tekniske problemer reduserte motivasjonen for videosamtale hos pasientene og hjemmesykepleierne og var medvirkende årsak til at 2 av 17 pasienter gjenopptok hjemmebes $\emptyset \mathrm{k}$ i siste del av behandlingen. I andre studier har 4-13\% av pasientene gjenopptatt hjemmebesøk grunnet tekniske problemer, lav etterlevelse og/eller $\emptyset$ nske om hjemmebes $\varnothing \mathrm{k}$ fremfor videosamtale $(9,13,16)$. Videosamtale krever at pasienten deltar mer aktivt i behandlingen (23). Dette kan være hensiktsmessig i deler av behandlingsperioden, men ikke nødvendigvis i hele (7).

Hjemmebesøk passer ikke alltid inn i pasientens $\operatorname{liv}(8,24)$. I vår studie muliggjorde videosamtale observasjon av medikamentinntaket for pasienter som skulle på reise eller ville unngå oppmerksomhet fra naboer. Flertallet av pasientene jobbet eller studerte, og over halvparten utførte videosamtale både i og utenfor hjemmet. Andre studier har vist at $\emptyset \mathrm{kt}$ konfidensialitet og fleksibilitet ved videosamtale kan redusere antall dager med forhåndsavtalt egenadministrasjon og bidra til at flere pasienter fullfører tuberkulosebehandlingen $(9,10,14,16)$.

Direkte observert behandling ved videosamtale er vist å være kostnadseffektivt, og i flere studier er det funnet tidsbruk på om lag 5 minutter per videosamtale (10, 22, 23). I vår studie var tidsbruken enda lavere.

I tråd med andre studier rapporterte de fleste av pasientene at taushetsplikten ble bedre ivaretatt ved videosamtale enn hjemmebesøk $(13,14,16)$. Vi fant at flertallet av pasientene og hjemmesykepleierne foretrakk videosamtale fremfor hjemmebes $ø \mathrm{k}(10,13,16)$. Vi erfarte at de pasientene som foretrakk hjemmebesøk, også hadde behov for andre hjemmesykepleietjenester ut over tuberkulosebehandlingen.

Så vidt vi vet er dette den første studien av direkte observert behandling ved videosamtale $\mathrm{i}$ 
Norden. I vår studie ble videosamtale utført sju dager i uken mens noen studier i USA har utført videosamtale bare fem dager per uke $(9,16)$. Studien begrenses av få deltakere, manglende kontrollgruppe og at videosamtaletjenesten ikke kunne loggføre utført videosamtale og tidsbruk. Hjemmesykepleiens registrering på papirskjema medførte varierende datakvalitet og manglende data.

\section{Konklusjon}

Direkte observert behandling ved videosamtale var gjennomførbart for utvalgte pasienter, ga høy andel observerte medikamentinntak og var tidsbesparende for hjemmesykepleien. Flertallet av pasientene og hjemmesykepleierne foretrakk videosamtale fremfor hjemmebes $\emptyset \mathrm{k}$ og ville anbefalt dette til andre. Videosamtale fungerte best når både pasient og hjemmesykepleier var punktlige. Basert på resultater fra studien har vi videreført direkte observert behandling ved videosamtale for pasienter med tuberkulosesykdom ved Universitetssykehuset Nord-Norge, Tromsø.

Videreutvikling av teknologi for videosamtaler vil redusere antall tekniske og praktiske problemer og gjøre videosamtale mer brukervennlig. Studien tilbød videosamtale til pasienter $\geq 16$ år med tuberkulosesykdom. Fremtidige studier bør undersøke bruk av videosamtale blant yngre personer.

\section{HOVEDFUNN}

Direkte observert behandling av tuberkulose ved videosamtale var gjennomførbart for utvalgte pasienter.

Videosamtale var tidsbesparende for hjemmesykepleien og ble foretrukket av flertallet av pasienter og hjemmesykepleiere.

\section{LITTERATUR:}

1. Folkehelseinstituttet. Tuberkuloseveilederen. https://www.fhi.no/nettpub/tuberkuloseveilederen/ Lest 8.11.2019.

2. Arnesen TM, Heldal E, Mengshoel AT et al. Tuberkulose i Norge 2017-med behanlingsresultater for 2016. Oslo: Folkehelseinstituttet, 2018.

https://www.fhi.no/globalassets/dokumenterfiler/rapporter/2018/arsrapport-tuberkulose-i-norge-2017.pdf Lest 8.11.2019.

3. Arnesen TM, Heldal E, Mengshoel AT et al. Tuberkulose i Norge 2018 - med behanlingsresultater for 2017. Oslo: Folkehelseinstituttet, 2019.

https://www.fhi.no/contentassets/fd326ofd299f4ad3bao74co49debraeg/tuberkulose-arsrapport-2019-ti l-publisering.pdf Lest 8.11.2019.

4. The End TB Strategy. Geneve: World Health Organization, 2015.

https://www.who.int/tb/End_TB_brochure.pdf?ua=1 Lest 8.11.2019.

5. LOV-1999-07-02-63. Lov om pasient- og brukerrettigheter.

https://lovdata.no/dokument/NL/lov/1999-07-02-63/\#KAPITTEL_3 Lest 8.11.2019.

6. FOR-2009-02-13-205. Forskrift om tuberkulosekontroll.

https://lovdata.no/dokument/SF/forskrift/2009-02-13-205 Lest 8.11.2019.

7. Guidelines for treatment of drug-susceptible tuberculosis and patient care. 2017 update. Geneve:

World Health Organization, 2017.

https://apps.who.int/iris/bitstream/handle/10665/255052/97892415500oo-eng.pdf;jsessionid-

EF262126BC71C95C384A1D7CC3453312?sequence=1 Lest 8.11.2019.

8. Sagbakken M, Bjune GA, Frich JC. Humiliation or care? A qualitative study of patients' and health professionals' experiences with tuberculosis treatment in Norway. Scand J Caring Sci 2012; 26: 313-23. 
9. Holzman SB, Zenilman A, Shah M. Advancing patient-centered care in tuberculosis management: A mixed-methods appraisal of video directly observed therapy. Open Forum Infect Dis 2018; 5: ofyo46. [PubMed][CrossRef]

10. Mirsaeidi M, Farshidpour M, Banks-Tripp D et al. Video directly observed therapy for treatment of tuberculosis is patient-oriented and cost-effective. Eur Respir J 2015; 46: 871-4. [PubMed][CrossRef]

11. Direktoratet for e-helse. Nasjonal e-helsestrategi 2017-2022.

https://ehelse.no/strategi/nasjonal-e-helsestrategi-og-handlingsplan-2017-2022 Lest 18.1.2019

12. Helse Nord. Helse Nords strategi.

https://helse-nord.no/om-oss/hva-gjor-helse-nord-rhf/helse-nords-strategi\#informasjonsteknologi-ogtelemedisin Lest 8.11.2019.

13. Garfein RS, Collins K, Muñoz F et al. Feasibility of tuberculosis treatment monitoring by video directly observed therapy: a binational pilot study. Int J Tuberc Lung Dis 2015; 19: 1057-64. [PubMed][CrossRef]

14. Wade VA, Karnon J, Eliott JA et al. Home videophones improve direct observation in tuberculosis treatment: a mixed methods evaluation. PLoS One 2012; 7: e50155. [PubMed][CrossRef]

15. Story A, Aldridge RW, Smith CM et al. Smartphone-enabled video-observed versus directly observed treatment for tuberculosis: a multicentre, analyst-blinded, randomised, controlled superiority trial. Lancet 2019; 393: 1216-24. [PubMed][CrossRef]

16. Garfein RS, Liu L, Cuevas-Mota J et al. Tuberculosis treatment monitoring by video directly observed therapy in 5 health districts, California, USA. Emerg Infect Dis 2018; 24: 18o6-15. [PubMed][CrossRef]

17. Norsk Helsenett. https://www.nhn.no/helsenettet/eksisterende-medlem/ Lest 15.1.2019.

18. LOV-2018-06-15-38. Lov om behandling av personopplysninger.

https://lovdata.no/dokument/NL/lov/2018-o6-15-38/*\#KAPITTEL_4 Lest 8.11.2019.

19. LOV-1999-07-02-64. Lov om helsepersonell

https://lovdata.no/dokument/NL/lov/1999-07-02-64/KAPITTEL_5\#KAPITTEL_5 Lest 8.11.2019.

20. FOR-2019-03-01-168. Forskrift om pasientjournal.

https://lovdata.no/dokument/SF/forskrift/2019-03-01-168 Lest 8.11.2019.

21. Norsk Helsenett. Video produktark. https://www.nhn.no/media/1644/video-produktark.pdf Lest 15.1.2019.

22. Chuck C, Robinson E, Macaraig M et al. Enhancing management of tuberculosis treatment with video directly observed therapy in New York City. Int J Tuberc Lung Dis 2016; 20: 588-93. [PubMed][CrossRef]

23. Krueger K, Ruby D, Cooley P et al. Videophone utilization as an alternative to directly observed therapy for tuberculosis. Int J Tuberc Lung Dis 2010; 14: 779-81. [PubMed]

24. Story A, Garfein RS, Hayward A et al. Monitoring therapy compliance of tuberculosis patients by using video-enabled electronic devices. Emerg Infect Dis 2016; 22: 538-40. [PubMed][CrossRef]

Publisert: 13. januar 2020. Tidsskr Nor Legeforen. DOI: 10.4045/tidsskr.19.0322

Mottatt 30.4.2019, første revisjon innsendt 10.7.2019, godkjent 8.11.2019.

(C) Tidsskrift for Den norske legeforening 2020. Lastet ned fra tidsskriftet.no 